\title{
PANORAMA SOBRE OS TRANSPLANTES DE ÓRGÃOS NO BRASIL E FATORES ASSOCIADOS À BAIXA ADESÃO À PRÁTICA
}

\author{
An overview on organ transplants in Brazil and factors associated with low \\ adhesion of the practice \\ Marina Brandalise, Natália Pagnussat
}

\section{RESUMO}

Há séculos, a humanidade busca a substituição dos órgãos que apresentam alguma patologia, por órgãos sadios, mas, somente em poucas décadas esse procedimento tornou-se possível, através dos transplantes de órgãos. Existe grande desarmonia entre o número de doadores, quando comparado à demanda de órgãos. Milhares de pessoas no mundo todo aguardam na fila de transplantes e esse número vem aumentando gradativamente. Isso pode estar associado à desinformação, prejudicando o desenvolvimento e, consequentemente, implicando na diminuição dos índices de captação. Objetivo: Conhecer e apontar os principais fatores associados à baixa adesão aos transplantes de órgãos no Brasil, assim como compreender o que é e do que consiste o processo de transplantes de órgãos no país. Métodos: Estudo observacional com base na revisão de literatura científica, com utilização de 10 artigos base. Resultados: Percebe-se certo grau de desconhecimento acerca do tema transplante de órgãos, o que consequentemente vem refletindo nas atitudes dos familiares e componentes das equipes de saúde que trabalham diretamente com o paciente doador. Conclusão: O estudo destaca a presença de fatores associados aos baixos índices nos procedimentos acerca dos transplantes de órgãos, como: crença e religiosidade, dúvidas e desconhecimento dos protocolos que fazem parte do processo de doação, tanto pelos membros da família quanto pela equipe médica, até a dúvida sobre a opinião do ente querido em relação ao assunto "ser ou não doador", pois não tivera a oportunidade de deixar explícito seu desejo, antes do acontecimento que o tornara um potencial doador.

Descritores: Doadores Vivos; Morte Encefálica; Obtenção de Tecidos e Órgãos; Transplantes.

\section{Instituição:}

Curso de Graduação em Enfermagem da Faculdade da Serra Gaúcha de Caxias do Sul, Rio Grande do Sul, Brasil.

\section{Correspondência:}

Marina Brandalise

Rua Dr. Montaury, 551, Centro, CEP 95270-000, Flores da Cunha/RS

Tel.: (54) 3292-1865

E-mail: nina.brandalise@hotmail.com

\section{INTRODUÇÃO}

Há séculos, a humanidade busca a substituição de órgãos que apresentem alguma patologia, por órgãos sadios, mas somente em poucas décadas esse procedimento tornou-se possível, por meio dos transplantes de órgãos. Esse contexto está diretamente relacionado à qualidade e sobrevida do paciente..$^{1-3} \mathrm{Em}$ 1965, foi realizado o primeiro transplante renal com doador vivo no Brasil, em São Paulo, no Hospital das Clínicas e, em 1967, com doador falecido. ${ }^{4,5}$

Dados disponibilizados no Sistema Nacional de Transplantes (SNT) mostram que, em 2014, foram realizados no Brasil 23.226 transplantes. Os maiores índices de procedimentos foram referentes ao tecido ocular, com 13.456 transplantes, representando 58\% da totalidade, seguidos pelos transplantes de rim, com 5.409 casos. $^{6}$ 
Com base no desenvolvimento da tecnologia, os transplantes tiveram seu conceito modificado, ao passo que antes eram vistos apenas como uma terapia de grau experimental e, agora, tornaram-se uma terapia de escolha, a critério do paciente com alguma falência de órgão. Tal posição foi possível graças aos grandes avanços nas áreas de terapia intensiva, imunologia e farmacologia. ${ }^{7,8}$

Porém, para que esse processo possa ocorrer, é necessário que haja, primeiramente, colaboração e aceitação da sociedade. Havendo visível diferença numeral entre a quantidade de doadores e a demanda de órgãos, na medida em que as listas de espera são amplificadas, o número de mortes relacionadas à espera também crescem. Dentre os principais fatores limitantes decisivos, está a recusa familiar da prática da doação, não só no Brasil, mas também em outros países do mundo. ${ }^{8-10}$

Quais os principais fatores que estão associados à baixa adesão dessa prática no Brasil? Este estudo tem como objetivo conhecer e apontar os principais fatores que estão associados à baixa adesão aos transplantes de órgãos no Brasil e compreender o que é e em que consiste o processo de transplantes de órgãos no país.

\section{REFERENCIAL TEÓRICO}

\section{Transplantes de órgãos e conceito de morte encefálica}

O processo de transplante de órgãos consiste em um procedimento cirúrgico que visa a reposição de órgãos (coração, pulmão, rins, fígado, pâncreas, intestino) ou tecidos (medula óssea, ossos, válvulas, músculos, pele, córneas, veias e artérias) que apresentem alguma patologia clínica, comprometendo o funcionamento do próprio órgão e a vida do paciente doente (receptor). Dessa forma, o procedimento é feito por meio de um doador vivo ou falecido. ${ }^{11}$ Porém, a avaliação do potencial doador em vida deve considerar a inexistência de contraindicações clínicas e laboratoriais à doação, sendo que não podem ser considerados doadores, por exemplo, pacientes portadores de insuficiência orgânica que comprometa o funcionamento dos órgãos e tecidos, assim como outros aspectos: ser portador de doença infecto contagiosa (HIV, hepatites, doença de Chagas), além da realização de exames laboratoriais. ${ }^{11}$

O conceito de morte encefálica teve início por volta de 1959, com a criação do termo "coma depassé", sendo possível manter as funções básicas do organismo mesmo sem o funcionamento do encéfalo. A morte encefálica foi definida, a partir da Harvard Medical School, em 1969, como o déficit estrutural e/ou funcional do encéfalo como órgão de função integrado ao organismo humano. A partir desses dados, foi possível comprovar grandes avanços no ramo da Medicina e demonstrar a importância do diagnóstico de morte encefálica no processo de transplantes. Basicamente, o processo de morte encefálica inicia-se com o aumento da pressão intracraniana, devido à expansão volumétrica do conteúdo intracraniano. Durante essa expansão, o conteúdo liquórico é drenado e o retorno venoso é comprometido, elevando progressivamente a pressão intracraniana, uma vez que a hipóxia celular e o edema contribuem para esse aumento. Esse processo atinge o ponto mais alto, com a herniação transtentorial do tronco cerebral pelo forâmen magno que bloqueia completamente a única via de saída, elevando a pressão intracraniana, até o momento que interrompe completamente a circulação arterial encefálica, ocorrendo então, a morte encefálica. . $^{8-12}$

Dessa forma, morte encefálica é a definição legal da morte do encéfalo, tendo por completa e irreversível a parada de todas as funções do cérebro, sendo proveniente de severa agressão ou ferimento, provocando o bloqueio do sangue e oxigênio em todos os tecidos locais. As principais causas da morte encefálica estão relacionadas à causa vascular (isquêmica ou hemorrágica), traumatismo crânio encefálico, tumores intracranianos e encefalopatia anóxica. ${ }^{11}$

Todo paciente que tiver constatada a morte encefálica será, automaticamente, considerado um potencial doador. ${ }^{11}$ No Brasil, o diagnóstico de morte encefálica é definido pela Resolução CFM No $1480 / 97,{ }^{15}$ devendo ser registrado em prontuário, também conhecido como Termo de Declaração de Morte Encefálica, descrevendo os elementos do exame neurológico que demonstrem ausência dos reflexos do tronco cerebral, bem como o relatório de exame complementar.

Faz-se necessária a adoção de critérios para constatar a ocorrência da morte, sendo imprescindível a realização de dois exames clínicos e um exame complementar. É de extrema importância a notificação por morte cerebral de um paciente, e o profissional responsável por comunicar a família deve ser o médico, psicólogo ou o coordenador da unidade de transplantes. ${ }^{16}$

\section{Em que consiste o processo de transplantes no Brasil}

Os anos de 1960 foram marcados pelos primeiros procedimentos de transplantes renais do Brasil. Em 1968, na cidade de São Paulo, ocorreu o primeiro transplante de coração, procedimento mediado pela equipe do Dr. Euryclides de Jesus Zerbini. A partir dessa época, houve aumento considerável em relação 
aos procedimentos relacionados aos transplantes de órgãos no país, bem como o aumento da prática, de forma geral. Mesmo que na época vigorasse a Lei 5.479 de 1968 (posteriormente substituída pela lei 8.489 de 1992), que norteava a retirada de órgãos e tecidos para fins terapêuticos, até então, não havia legislação que regulamentasse tal atividade. ${ }^{4,17}$

Devido à grande parte dos procedimentos ser realizada com recursos públicos, surgiu a necessidade de regulamentar a prática, criando uma coordenação de nível nacional para o sistema de transplantes. Em 1997, foi publicada a Lei dos Transplantes $n^{\circ} 9.434,{ }^{18}$ com a principal finalidade de dispor sobre a remoção de órgãos, tecidos e outras partes do corpo humano de forma gratuita, bem como, o Decreto 2.268 que instituiu o Sistema Nacional de Transplantes (SNT) no âmbito do Ministério da Saúde. ${ }^{17}$

A Lei $9.434 / 97$ foi regulamentada pelo Decreto $\mathrm{N}^{\circ}$ $2268 / 97,{ }^{19}$ que estabeleceu também o Sistema Nacional de Transplantes (SNT), os Órgãos Estaduais e as Centrais de Notificação, Captação e Distribuição de Órgãos (CNCDOs), ressaltando a obrigatoriedade de todos os serviços de saúde do estado realizarem o diagnóstico de morte encefálica quando ocorrer o óbito. Em 2001, extinguiu-se a doação presumida no Brasil e ficou determinado que a doação com doador falecido só deve ocorrer com a autorização familiar, independente do desejo em vida do potencial doador. As manifestações de vontade relativas à retirada "post mortem" de tecidos, órgãos e partes, registradas na Carteira de Identidade Civil e na Carteira Nacional de Habilitação, perderam sua validade a partir de 22 de dezembro de $2000 .^{4,7,20}$

Desde então, os procedimentos de transplantes no Brasil só podem ser realizados através de estabelecimentos de saúde credenciados e autorizados pelo gestor nacional do Ministério da Saúde. Desta forma, foi instituída uma lista única de receptores, os quais são separados por tipos de órgãos e tipos sanguíneos, entre outras especificações, sob controle das Secretarias Estaduais de Saúde. ${ }^{4}$

A partir de uma avaliação clínica médica, testes especiais e de compatibilidade sanguínea, é possível realizar o procedimento de transplante por meio de um doador vivo, podendo-se obter deste apenas um dos rins ou pulmões, parte do fígado e a medula óssea, a fim de não comprometer a saúde do doador. ${ }^{4}$

Após a realização da captação, a Central de Transplantes do Estado é comunicada e selecionam-se então, por meio de uma lista de espera, os receptores mais compatíveis. ${ }^{7}$

Sendo assim, o processo de transplante de órgãos ou tecidos divide-se em diversas etapas: constatação de potencial doador, avaliação, manutenção, diagnóstico de morte encefálica quando houver, opinião familiar, documentação para comprovação da morte encefálica, remoção e distribuição do material coletado, transplante e acompanhamento especial do transplantado. ${ }^{20}$

\section{Fatores associados à baixa adesão da prática de transplantes}

A grande maioria da população recebe informações referentes aos transplantes e doação de órgãos através de diferentes meios de comunicação, como a televisão, rádio, internet, jornais e revistas. ${ }^{7}$ Uma porcentagem menor recebe influência de parentes e amigos, porém essas informações não representam de forma geral a população, sendo incapaz de esclarecer dúvidas e eliminar a insegurança acerca do tema. ${ }^{21,22}$

Há grande desarmonia entre o número de doadores, quando comparado à demanda de órgãos. Milhares de pessoas no mundo todo aguardam na fila de transplantes e esse número vem aumentando gradativamente. Isso pode estar associado com a desinformação, prejudicando o desenvolvimento e, consequentemente, implicando na diminuição dos índices de captação. 9,10,23

O perfil do indivíduo que, normalmente, não é a favor da doação de órgãos, caracteriza-se principalmente por: idade acima de 45 anos, ambos os sexos, baixa escolaridade, não compreende o real significado do termo "morte encefálica", enquadra-se como sendo evangélico ou testemunha de Jeová, apresentando medo e receio da manipulação de seu corpo após a morte. ${ }^{7,24,25}$

Nota-se ainda a escassez de recursos na captação de órgãos e tecidos, salientando-se a falta de estrutura adequada para a realização dos procedimentos, assim como profissionais capacitados especificamente para essa função. ${ }^{4}$

A notificação compulsória de morte encefálica (ME) para as centrais de transplantes é ainda desconhecida por grande parte dos médicos e enfermeiros entrevistados, onde os quais não se responsabilizavam pela falta do ato de comunicação, sendo que apenas $25 \%$ dos entrevistados já haviam realizado a notificação de um caso de $\mathrm{ME}$, havendo falha no repasse dos dados. ${ }^{26,27}$

Para que haja diminuição dos fatores associados à baixa adesão, sugerem-se algumas estratégias e, dentre elas, a atuação na prevenção de doenças, assim como a promoção de saúde, evitando que as pessoas venham a necessitar de um transplante. ${ }^{4} \mathrm{Em}$ relação ao progresso médico, devem-se buscar diferentes medidas terapêuticas, como por exemplo, a utilização de células-tronco, e reforçar as campanhas em relação ao tema, com abordagens éticas que visem a melhoria no interesse do doador e do receptor. ${ }^{28-30}$ 


\section{MÉTODOS}

\section{Tipo de estudo}

Visando abordar questões sobre os transplantes de órgãos no Brasil, bem como os principais fatores associados à baixa adesão da prática, optou-se pelo método da revisão da literatura científica, na medida em que essa modalidade possibilita sumarizar as pesquisas já concluídas e obter conclusões a partir de um tema de interesse, caracterizando-se como um estudo observacional.

\section{Estratégias de busca}

A base de dados selecionada para pesquisa dos artigos foi a Scielo.Org, com fundamento nos descritores: doadores vivos, morte encefálica, obtenção de tecidos e órgãos, e transplantes.

\section{Critérios de elegibilidade}

Foram adotados, como critério de escolha e inclusão, aqueles artigos que apresentaram especificidade com o tema abordado e correlação com os objetivos descritos (conhecer e apontar os principais fatores associados à baixa adesão ao transplante de órgãos no Brasil e compreender o que é e de que forma consiste o processo de transplantes de órgãos), respeitando o período supracitado de 10 anos, a partir de 2005.

\section{ANÁLISE E DISCUSSÃO DOS RESULTADOS}

De acordo com o tema escolhido neste artigo, foram selecionados 30 artigos, de modo aleatório. Com base nos critérios de elegibilidade, na leitura e resultados destes, permaneceram 10 artigos, que contribuíram para a formulação e interpretação dos principais dados, como mostra a Figura 1.

Comparando os resultados apontados pelos autores de cada artigo selecionado, obtidos de forma resumida, pode-se observar certo grau de desconhecimento acerca do tema transplante de órgãos, que consequentemente vem se refletindo nas atitudes dos familiares e componentes das equipes de saúde que trabalham diretamente com o paciente doador. $O$ embasamento e a construção da opinião acerca dos transplantes de órgãos são essencialmente importantes na área dos profissionais de saúde. Por mais que haja sinais de evolução, nota-se que esse assunto ainda recebe pouca atenção em ambiente acadêmico. ${ }^{23,26}$ Ressalta-se que $70 \%$ dos 347 estudantes entrevistados classificaram o grau de conhecimento sobre o tema como regular, ruim ou péssimo. ${ }^{23}$ Sob o aspecto da alocação de órgãos, $64 \%$ dos estudantes consideraram que o procedimento de doação e transplantes deveria ser realizado de acordo com o tipo específico da doença, ou seja, conforme a urgência da patologia. Com opiniões distintas, $60 \%$ dos 303 adultos entrevistados eram a favor de que as crianças tivessem prioridade no transplante de órgãos; já $75 \%$ optaram pelos idosos com idade acima de 65 anos, e que o debate em torno do tema só passasse a ganhar força à medida que houvesse evolução dos cursos acadêmicos e o conhecimento da importância desse ato. ${ }^{16}$

O trabalho de Schirmer et al. (2006): "Legislação sobre doação de órgãos e tecidos: o que pensam os profissionais de UTI?", permite diagnosticar que $20 \%$ dos 40 profissionais da saúde entrevistados desconheciam a nova regulamentação da lei, que determina a necessidade do consentimento da família do doador para a doação de seus órgãos; por ora, esse desconhecimento referente à legislação também foi percebido em até $55 \%$ dos médicos e enfermeiros. ${ }^{26}$ De acordo com a equipe de saúde, composta por médicos e enfermeiros, $10 \%$ desconhecia os critérios pré-estabelecidos para o diagnóstico de morte encefálica (ME). Dentro dessa mesma classificação, $40 \%$ dos profissionais da área não tinham informações sobre os exames clínicos necessários para a realização do diagnóstico e notificação compulsória de ME; apenas $25 \%$ haviam notificado um caso durante sua carreira.

Com base em dados populacionais, $99 \%$ do público entrevistado já havia ouvido falar sobre doação e transplantes, $65 \%$ havia informado a família sobre o desejo de ser doador e $90 \%$ dos familiares concordaram com a retirada de órgãos nos casos em que o paciente apresentara ME. Nesse sentido, o resultado pode estar associado ao trabalho da reformulação de ideias e esclarecimentos à população. ${ }^{16}$

De modo geral, há atitude positiva da população mundial acerca da doação de órgãos e transplantes, que varia de $52 \%$ a $80 \%$, frisando que o fator chave para que os familiares decidam a favor da doação é terem discutido o assunto previamente com o paciente/ familiar e conhecido sua vontade de tornar-se um doador. $^{7}$

Muitos fatores são decisivos e contribuem para a queda nas taxas de captação e adesão aos transplantes. Dez principais motivos da recusa são descritos, classificando-se como: crença religiosa, espera de um milagre, não compreensão do diagnóstico de $\mathrm{ME}$ e crença na reversão do quadro, não aceitação da família, inadequação na informação e ausência de confirmação da ME, desconfiança na assistência e medo do comércio de órgãos, inadequação no processo de doação, e por fim, medo da perda do ente querido. ${ }^{27}$ 
Figura 1 - Descrição dos resultados

\begin{tabular}{|c|c|c|c|}
\hline Autores & $\begin{array}{c}\text { Ano de } \\
\text { Publicação }\end{array}$ & $\begin{array}{l}\text { Número de participantes / } \\
\text { Tipo de estudo }\end{array}$ & Resultados \\
\hline Abbud, M.F. & 2006 & $\begin{array}{l}\text { Editorial do Jornal Brasileiro de } \\
\text { Transplantes, v.09, n.01 com base } \\
\text { no trabalho de Schirmer e cols. }\end{array}$ & $\begin{array}{l}20 \% \text { dos entrevistados não sabiam que a doação de órgãos necessitava } \\
\text { do consentimento familiar. } 5 \% \text { a } 55 \% \text { dos médicos e enfermeiras } \\
\text { interpretavam erradamente a lei, } 10 \% \text { desconhecia a regulamentação } \\
\text { dos critérios utilizados para o diagnóstico de ME, } 40 \% \text { não tinha } \\
\text { informação sobre os exames clínicos necessários para se fazer o } \\
\text { diagnóstico. A notificação compulsória de ME era desconhecida } \\
\text { por } 27 \% \text { a } 34 \% \text { dos médicos e enfermeiras, apenas } 25 \% \text { tinha } \\
\text { experimentado notificar um caso. }\end{array}$ \\
\hline $\begin{array}{l}\text { Cicolo, E.A.; Roza, B.A.; } \\
\text { Schirmer, J. }\end{array}$ & 2010 & 30 artigos - Revisão bibliográfica & $\begin{array}{l}\text { Faz-se necessário um maior número de estudos científicos } \\
\text { desenvolvidos pela enfermagem de todo o país, sobre os diversos } \\
\text { aspectos da doação e transplantes de órgãos. }\end{array}$ \\
\hline D’Império, F. & 2007 & Revisão bibliográfica & $\begin{array}{l}\text { É necessário esforço para aprimorar técnicas existentes na captação e } \\
\text { preservação, desenvolver novas medidas para o seu aproveitamento de } \\
\text { forma a reduzir a mortalidade nas filas de espera. }\end{array}$ \\
\hline Faria, J.G. et al. & 2007 & $\begin{array}{l}\text { Questionário - } 303 \text { adultos, sendo } \\
52 \% \text { do sexo feminino }\end{array}$ & $\begin{array}{l}99 \% \text { haviam ouvido falar sobre doação e transplantes. } 65 \% \text { haviam } \\
\text { informado a família sobre o desejo de doar. } 90 \% \text { concordou com a } \\
\text { retirada de órgãos de paciente em ME. } 60 \% \text { opinaram que crianças } \\
\text { deveriam ter prioridade e } 75 \% \text { os idosos. }\end{array}$ \\
\hline Galvão, F.H.F. et al. & 2007 & Questionário - 347 estudantes & $\begin{array}{l}70 \% \text { dos estudantes admitiram conhecimento regular, ruim ou } \\
\text { péssimo do assunto. } 64,3 \% \text { optaram pela gravidade da doença como } \\
\text { forma de alocação. O entendimento sobre transplante aumentou } \\
\text { conforme o avanço do curso de graduação. }\end{array}$ \\
\hline Hummel, A.D. et al. & 2009 & $\begin{array}{l}\text { Revisão bibliográfica - } 89 \text { artigos } \\
\text { selecionados em primeiro } \\
\text { momento, após } 05 \text { artigos. }\end{array}$ & $\begin{array}{l}\text { Estudos mostraram que redes neurais artificiais e regressão logística } \\
\text { obtêm bons resultados quando aplicados em bases de dados de } \\
\text { transplantes e órgãos para descoberta de conhecimento, apresentam } \\
\text { resultados animadores em suas respectivas bases de dados de estudo. }\end{array}$ \\
\hline Lazzaretti, C.T. & 2007 & Revisão bibliográfica & $\begin{array}{l}\text { Nas condições atuais de desenvolvimento tecnológico e do saber } \\
\text { médico, a dádiva adquire nova dimensão, a solidariedade, a } \\
\text { generosidade e o altruísmo como justificativa do ato de doação de } \\
\text { parte de seu corpo podem ser pensadas como uma das maneiras de o } \\
\text { homem lidar com sua condição de desamparo. }\end{array}$ \\
\hline $\begin{array}{l}\text { Moraes, E.L.; } \\
\text { Massarollo, M.C.K.B. }\end{array}$ & 2009 & $\begin{array}{l}\text { Pesquisa qualitativa }-08 \text { familiares } \\
\text { que recusaram a doação de } \\
\text { órgãos e tecidos. }\end{array}$ & $\begin{array}{l}\text { Foram revelados } 10 \text { motivos de recusa, estando relacionados à crença, } \\
\text { valores e inadequações no processo de doação e transplante (a crença } \\
\text { religiosa, a espera de um milagre, a não compreensão do diagnóstico } \\
\text { de ME e a crença da reversão do quadro, a não aceitação da família, } \\
\text { a inadequação na informação e a ausência de confirmação da ME, } \\
\text { a desconfiança na assistência e o medo do comércio de órgãos, a } \\
\text { inadequação no processo de doação, o medo da perda do ente querido). }\end{array}$ \\
\hline $\begin{array}{l}\text { Ribeiro, C.D.M.; } \\
\text { Schramm, F.R. }\end{array}$ & 2006 & $\begin{array}{l}\text { Abordagem teórica } \\
\text { (teoria das capacidades e a } \\
\text { bioética da proteção). }\end{array}$ & $\begin{array}{l}\text { Problema da escassez de recursos na área de transplantes. Adotar } \\
\text { políticas de focalização na área da atenção médica avançada. }\end{array}$ \\
\hline $\begin{array}{l}\text { Traiber, C.; } \\
\text { Lopes, M.H.I. }\end{array}$ & 2006 & $\begin{array}{l}\text { Pesquisa bibliográfica com } \\
\text { artigos de } 1996 \text { - } 2006 .\end{array}$ & $\begin{array}{l}\text { Existe atitude positiva da população mundial acerca da doação de } \\
\text { órgãos e transplantes que varia de } 52 \% \text { a } 80 \% \text {. Um dos fatores mais } \\
\text { importantes para que os familiares decidam a favor da doação de } \\
\text { órgãos é o fato de ter discutido previamente com o paciente sobre a } \\
\text { doação. }\end{array}$ \\
\hline
\end{tabular}

A importância das pesquisas científicas na área da saúde, em relação aos transplantes de órgãos e os diversos aspectos referentes à doação, é enfatizada, visando o envolvimento da equipe de enfermagem de todo o país, o aprimoramento das técnicas de captação e preservação dos órgãos, desenvolvimento de novas medidas para o aproveitamento de forma a reduzir a mortalidade nas filas de espera. ${ }^{8,20}$ É de extrema importância a utilização de uma base de dados, na qual as equipes de saúde possam encontrar, além dos dados propriamente ditos, o conhecimento específico sobre a demanda de órgãos e a real situação do Brasil, de forma a contribuir para os estudos. ${ }^{1}$

Cita-se ainda a escassez de recursos na área dos transplantes como outro fator que contribui para a baixa adesão das cirurgias de transplantes no país, bem 
como a precariedade de políticas focalizadas na área da atenção médica avançada. ${ }^{4}$

É possível observar que, diante dos avanços médicos e tecnológicos, a ideia da doação de órgãos volta-se para a solidariedade, a generosidade e o altruísmo, que auxiliam no processo do desamparo da família que perdeu um ente querido, mas que por outro lado pôde salvar uma vida, proporcionando a convivência prolongada do transplantado com a sua família. ${ }^{2}$

\section{CONCLUSÃO}

Com o objetivo de promover e compartilhar conhecimentos, o presente estudo buscou na literatura dados que pudessem mostrar o panorama real das condições em relação aos transplantes e doação de órgãos no Brasil. Sabe-se que é de extrema importância a conscientização da população sobre o tema, o esclarecimento das dúvidas e, principalmente, a participação da família em momento oportuno, ao responder por seu ente querido sobre a decisão de ser doador.

Com base nas pesquisas citadas no decorrer deste estudo, percebe-se que ainda existe grande discrepância em relação às pessoas que aguardam nas filas de espera para receber um órgão do qual necessitam e a realização do transplante. Essa realidade está associada a fatores que vão desde a crença e religiosidade, dúvidas e o desconhecimento dos protocolos que fazem parte do processo de doação, tanto pelos membros da família quanto pela equipe multidisciplinar de saúde, até a dúvida sobre qual a opinião do ente querido em relação ao assunto, pois não tiveram oportunidade de deixar explícito o seu desejo, antes do acontecimento que o tornara um potencial doador.

Para que essa realidade seja diferente, faz-se necessário um trabalho de conscientização da população, pelos meios de comunicação em massa, com campanhas nas redes de saúde de cada cidade, abordagem educativa nas escolas, cursos acadêmicos e até mesmo dentro das instituições de saúde, abrangendo todos os membros das equipes de saúde, uma vez que as competências clínicas necessárias vão além daquelas obtidas durante a graduação. $O$ trabalho em conjunto proporcionará mais segurança no repasse das informações, cumprimento dos protocolos exigidos por lei e principalmente, a compreensão de todos os processos envolvidos na doação e nos transplantes de órgãos. Cabe também ao estudante e futuro membro de uma equipe de saúde trabalhar para o desenvolvimento das pesquisas acerca dos transplantes, descobrindo novos métodos, técnicas de aproveitamento e manejo, evidenciando os fatores que implicam no fluxo normal de qualquer processo, proporcionar melhor qualidade de vida ao paciente transplantado mediante os cuidados e oferecer apoio à família que perdeu seu ente querido, mas que de alguma forma recebe o conforto em salvar uma vida, devolvendo a esperança e a participação do transplantado perante a sociedade, formando um ciclo de união e ajuda ao próximo.

\section{ABSTRACT}

For centuries, the human kind has been searching for ways to replace organs presenting pathologies for healthy ones; however, such process only became feasible in the last decades through the organ transplants. There is a major imbalance between the amounts of donors when compared to the demand for organs. Thousands of people around the world are waiting for the transplant on a waiting list, and such amount is increasing. This may be associated with misinformation, hampering the development and consequently, resulting in decreasing rates. Purpose: To recognize and highlight major factors associated with the low amount of organ transplants in Brazil, furthermore how the procedure takes place in the country. Methods: observational study based on scientific literature. Results: it is perceived a level of lack of knowledge on the organ transplant topic, which in turn is reflected in the attitudes of family members and components of the health teams working directly with the donor patient. Conclusion: the study highlights the presence of factors related to the low indexes of organ transplant procedures, such as believes and religiosity, doubts and lack of knowledge on the protocols composing the organ transplant process, not only by family members, but even from the medical staff, and including the wish of the potential donor as to the matter of becoming or not a donor, because they had no opportunity to leave their explicit desire before the event that had made the person a potential donor.

Keywords: Live Donors; Brain Death; Obtaining Tissues and Organs; Transplants. 


\section{REFERÊNCIAS}

1. Hummel AD, Maciel RF, Falcão AEJ, Teixeira F, Mancini F, Costa TM, et al. Aplicação de técnicas computacionais em bases de dados de transplante: revisão de artigos publicados no biênio 2007-2008. JBT J Bras Transpl. 2009;1(12):1045-8.

2. Lazzaretti CT. Dádiva da contemporaneidade: doação de órgãos em transplante intervivos. Epistemo-Somática. 2007:4(1):50-61.

3. Küss R, Bourget P. An illustrated history of organ transplantation: the great adventure of the century. France: Laboratoires Sandoz, 1992.

4. Ribeiro CDM, Schramm FR. Atenção médica, transplante de órgão e tecidos e políticas de focalização. Cad. Saúde Pública. 2006;22(9):1945-53.

5. Ianhez, L.E. Transplante renal no Brasil: história, evolução e problemas atuais. J Bras Nefrol. 1994;16:05-16.

6. Portal da Saúde - Ministério da Saúde [homepage da Internet]. Estatísticas do Sistema Nacional de Transplantes [acesso em 2015 Mar 23]. Disponível em: http://portalsaude. saude.gov.br/images/pdf/2015/marco/23/transplantes2014-u.pdf

7. Traiber C, Lopes MHI. Educação para doação de órgãos. Scientia Medica. 2006;16(4):178-82.

8. D'império F. Morte encefálica, cuidados ao doador de órgãos e transplante de pulmão. Rev. Bras. de Terapia Intensiva. 2007;19(1):74-84.

9. Smirnoff LA, Gordon N, Hewlett J, Arnold RM. Factors influencing families consent for donation of solid organs for transplantation. JAMA. 2001;286(1):71-7.

10. Schulz HD, Gold S, Von Dem Knesebeck M, Koch U. Willingness to donate organs - Strategies to influence attitude. Psychother Psychosom Med Psychol. 2002;52(1):24-31.

11. Associação Brasileira de Transplante de Órgãos (ABTO) [homepage na Internet]. Entenda a doação de órgãos Decida-se pela vida [atualizada em 2002 Ago 06; acesso em 2015 Fev 24]. Disponível em: http://www.abto.org.br/ abtov03/Upload/file/entendadoacao.pdf.

12. Joost AB, Ploeg RJ. Effects of brain death on donor viability. Curr Opin Organ Transplant. 2001;6:75-82.

13. Elliot JM. Brain death. Trauma. 2003;5:23-42.

14. Committee of the Harvard Medical School. Brain Death. Harvard Medical School, 1969.

15. Conselho Federal de Medicina. Resolução CFM n. 1.480 de 08 de agosto de 1997. Diário Oficial da União, 1997.

16. Faria JG, Branco LM, Duarte PS, Miyazaki MCOS, AbbudFilho M. Doação de órgãos para transplantes: informação e opinião de moradores do interior do estado de São Paulo. JBT J Bras Transpl. 2007;10:752-55.
17. Portal da Saúde - Ministério da Saúde [homepage na Internet]. Sobre o Sistema Nacional de Transplantes [criado em 2014 Jun 16; acesso em 2015 Fev 15]. Disponível em: http://portalsaude.saude.gov.br/index.php/o-ministerio/ principal/secretarias/969-sas-raiz/dahu-raiz/transplantesraiz/snt-2/snt-2-linha-1-coluna-2/13426-sobre-o-sistemanacional-de-transplantes.

18. Brasil. Lei n. 9.434 de 04 de fevereiro de 1997. Dispõe sobre a remoção de órgãos, tecidos e partes do corpo humano para fins de transplante e tratamento e dá outras providências. Diário Oficial da União, 1997.

19. Brasil. Decreto n. 2.268. Regulamenta a Lei n. 9.434, de 04 de fevereiro de 1997, que dispõe sobre a remoção de órgãos, tecidos e partes do corpo humano para fins de transplante e tratamento e dá outras providências. Diário Oficial da União, 1997.

20. Cicolo EA, Roza BA, Schirmer J. Doação e transplante de órgãos: produção científica da enfermagem brasileira. Rev Bras Enferm. 2010;63(2):274-8.

21. Evers S, Farewell VT, Halloran PF. Public awareness of organ donation. CMAJ. 1988;138:237-9.

22. Conesa $C$, Ríos $A Z$, Ramírez $P$, Canteras $M$, Rodríguez MM, Parrilla P. Influence of different sources of information on attitude toward organ donation: a factor analysis. Transplant Proc. 2004;36(5)1245-48.

23. Galvão FHF, Caires RA, Azevedo-Neto RS, Mory EK, Figueira ERR, Otsuzi TS, et al. Conhecimento e opinião de estudantes de medicina sobre doação e transplante de órgãos. Rev Assoc Med Bras. 2007;53(5):401-6.

24. Conesa C, Ríos $A$, Ramírez $P$, Canteras $M$, Rodríguez MM, Parrilla P. Multivariate study of the psychosocial factors affecting public attitude towards organ donation. Nefrologia. 2005;25(6):684-97.

25. Dubois JM, Anderson, E. Attitudes toward death criteria and organ donation among healthcare personnel and the general public. Progress in Transplantation. 2006;16(1):65-73.

26. Abbud-Filho M. Desvendando as causas de não efetivação dos potenciais doadores de órgãos: educar para não punir... quem? JBT J Bras Transpl. 2006;9(1):467.

27. Moraes EL, Massarollo MCKB. Recusa de doação de órgãos e tecidos para transplante relatados por familiares de potenciais doadores. Acta Paul Enferm. 2009;22(2):131-5.

28. Berlinguer, G. Ética da saúde. São Paulo: Editora Hucitec; 1996.

29. Schramm FR. Bioética, economia e saúde: direito à assistência, justiça social, alocação de recursos. Rev Bras Cancerol. 2000;46:41-7.

30. Ribeiro CDM. "Quem vale a pena?" Valores éticos e disponibilidade de recursos: representações acerca de políticas públicas de atenção ao paciente renal crônico [Dissertação de Mestrado]. Rio de Janeiro: Escola Nacional de Saúde Pública Fundação Oswaldo Cruz, 1998. 